\title{
The Impact Of CoCo Bonds On Bank Value And Perceived Default Risk: Insights And Evidence From Their Pioneering Use In Europe \\ Carolin Schmidt, Heilbronn University and University of Tuebingen, Germany Ted Azarmi, Heilbronn University and University of Tuebingen, Germany
}

\begin{abstract}
Contingent convertible (CoCo) bonds convert to equity during financial distress. They help transfer the responsibility for bearing the costs of poor performance from the taxpayers to the bank owners. Our results are thus relevant for investors, financial decision-makers, and regulators. We analyze the effects of the pioneering use of CoCos in Europe by Lloyds Banking Group in 2009. The bank's motivation for the issue is explored, considering both its economic situation and the Basel III regulations. We document a reduction in the bank's market value following the announcement of the intention to issue CoCos. Simultaneously, the credit default swap spread goes up. This study suggests that CoCos can have a negative effect on a bank's creditworthiness and firm value.
\end{abstract}

Keywords: Contingent Convertible Bonds; CoCo Bonds; Bank Value; Default Risk

\section{INTRODUCTION}

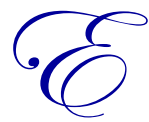
xotic financial products have been severely criticized in the aftermath of the financial crisis that started in 2007. Banks have to pay high premiums to attract investors who have become very uneasy about their investments after losing their trust in the banking system. Moreover, regulating institutions are searching for adequate measures to prevent another breakdown of the financial system. It is hence surprising that new financial products emerge that are often embraced unexpectedly positively by the investors. One of those new instruments is the contingent convertible $(\mathrm{CoCo})$ bond. This instrument behaves like a straight bond in times of economic wellbeing of the issuer. However, once the issuing bank's capital ratio falls below a certain threshold, the bond is converted into common stock. The resulting decrease in the bank's debt-equity ratio can lead to a considerable reduction of the bank's default probability. Also, upon conversion, the bank recapitalizes automatically and therefore bankruptcy costs that would arise otherwise are circumvented. CoCos are thus a valuable instrument to reduce the probability of bank default, costs, and to make the owners of a bank internalize the outcomes of poor performance. This makes CoCos publicly, economically and politically interesting.

In Europe, CoCos were for the first time issued by Lloyds Banking Group (LBG) in December of 2009 under the name of Enhanced Capital Notes. LBG, at that time partly owned by the British government after a bailout in 2008, pursued several objectives by this placement which will be explored in this study. Shortly after, other international banks followed. CoCos prove to be a widely-used instrument in Switzerland, as evidenced by the two Swiss major banks Credit Suisse and UBS that have very successfully issued CoCos or modified products in 2010. In particular, the trigger mechanism of the bonds is very popular. Although it was not possible for the Dutch cooperative Rabobank to place ordinary CoCos, the bank launched bonds with a write-down feature in 2011 (Financial Times, January 19, 2011). In the same year, Allianz was one of the first non-bank financial institutions (NBFIs) to issue CoCos. It is speculated that other NBFIs will follow (Reuters, July 5, 2011). 


\section{MOTIVATION}

The focus of research on financial instruments has changed during the last decade. Topics in the early 2000 's came mainly from the field of financial reporting, such as those studied by O'Brien (2005) or Marquardt \& Wiedmann (2007) who analyze the stock market reaction on disclosure requirements and changed earnings per share computations. The focus some years later shifted towards the pricing of claims using credit and equity derivatives approaches (e.g., DeSpiegeleer \& Schoutens 2012) and structural models (e.g., Albul, Jaffee \& Tchistyi 2010). Wilkens \& Bethke (2014) provide an empirical assessment of the most widely-used pricing methods. Nowadays, studies are concerned with the exposure to risk and the internalization of external effects (e.g., Pelger 2012). We contribute to the literature by analyzing the impact of CoCos on the conversion risk and by assessing the reaction of the capital and (credit default swap) CDS market to the issue announcement made by LBG. The results may be helpful to financial decision-makers, regulators, and investors.

The remainder of this paper is organized as follows. In Section 0, we will outline the features of CoCos that may make an issue attractive for a bank, its shareholders and for potential investors in general. From Section 0 on, we will shift our focus towards the case of LBG. This section investigates the rationale for LBG's CoCo issue in 2009, whereas the implications for the conversion risk and the bank's capital structure will be discussed in Section 0 . The main focus lies on Section 0, where we analyze the reaction of the stock market and the CDS market to the announcement that LBG plans a CoCo placement (November 3, 2009). This will be examined by use of an event study, covering the period from end of April to beginning of December 2009. Section 0 concludes.

\section{FEATURES OF CONTINGENT CONVERTIBLE BONDS}

CoCos are bonds with a conversion feature that is activated when a predefined event takes place. That is, before conversion CoCos are treated as straight bonds with a usual coupon, so that the bank can benefit or suffer from the features of common debt ${ }^{1}$. Upon conversion, the bank is equipped with fresh capital which may help it overcome phases of financial distress.

In Europe, CoCos are initially counted towards the lower tier 2 capital according to the Basel III regulations. However, once a conversion takes place, coupon payments are discontinued and the initial CoCo principal is classified as core tier 1 capital. The main advantage over straight bonds is that the credit burden is reduced during financial turbulences: whereas a straight bond coupon is fixed even when the bank is about to become insolvent, CoCos automatically convert into equity, reducing the bank's indebtedness and bolstering its capital resources. CoCos are thus instruments that cannot force the issuing bank into default. Given that the converted amount is classified as core tier 1 capital, CoCos are in line with the Basel III capital requirements, which is an incentive for banks to issue these instruments ${ }^{2}$.

The resulting lower default probability makes CoCos particularly interesting to the bank's shareholders since a conversion is triggered in the very moment when the bank reaches a certain point of distress. However, this is a double-edged sword for the initial shareholders: on the one hand, the shares of the initial and the new equity holders can then absorb the losses from the crisis as they are pooled, but on the other hand, the initial equity holders' shares are diluted. According to Flannery, CoCos 'provide market discipline by forcing shareholders to internalize more of their assets' poor outcomes' (see Flannery 2009, 1). I.e., the obligation to compensate for the bank's losses is directly transferred to the owners of the bank rather than to the taxpayers. Furthermore, since managers of systemically relevant banks know that the bank will be rescued by the state ('too big to fail' problem), it is expected that the equity holders will anticipate that overly risky projects could decrease the equity value.

\footnotetext{
${ }^{1}$ There are a number of benefits from debt, such as tax shields or a lower cost of capital. On the other hand, outstanding bonds make a bank riskier or can lead to inefficient decisions such as over- and underinvestment.

${ }^{2}$ Customers' deposits are a liability for the bank. Therefore, the balance sheet of a bank usually consists of about $95 \%$ of debt. This will be problematic with regards to the capital requirements of Basel III. For further information, see Zaehres (2011).
} 
But there is also a drawback for the holders of the CoCos in that they become shareholders in a rather disadvantageous point in time. There is a downside risk limited to the initial investment and a cap at the fixed coupon payments that is accounted for by a considerable risk premium on $\mathrm{CoCos}^{3}$.

In Europe, future perspectives regarding the size of the CoCo market vary. Zaehres (2011) proposes different scenarios and concludes that the market could grow to between EUR 38bn in the most conservative scenario and EUR 550bn at the best. The Telegraph reports that according to Barclays Capital, the market could be even worth EUR 700bn in 2018 (The Telegraph, February 8, 2011). Whether or not these numbers can be reached depends on the marketability of the CoCos, which is at the moment strongly limited due to the current credit ratings. This point will be discussed later in Section 0 .

\section{THE COCO ISSUE}

\subsection{The Context and Motivation of the Issue}

LBG was created in January 2009 after the British government initiated the acquisition of Halifax Bank of Scotland (HBOS) by Lloyds TSB. HBOS was severely hurt by the financial crisis whereas Lloyds got away without significant damage. As Lloyds was not able to finance the whole merger by itself, the government injected GBP $17 \mathrm{bn}$ in 2008 and since then had held roughly 43\% of the bank's shares (The Guardian, March 7, 2009). Despite the state support, the takeover of HBOS resulted disastrous for Lloyds, which is why it was offered to participate in the Government Asset Protection Scheme (GAPS). This rescue plan involved insuring LBG's toxic loans for GBP $260 \mathrm{bn}$ in exchange for an insurance fee and an increase of the government's stake to 65\% (BBC News, March 7, 2009). LBG accepted the deal in March 2009.

The market had already speculated that LBG would not further participate in the GAPS several days before it publicly declared its intention to withdraw from the GAPS and rather raise new capital privately on November 3 , 2009. Apparently, the insurance fees were too high for the bank and it saw itself in the position to find a private sector solution. In a letter to its shareholders the bank announced the intention to raise GBP 13.5bn in a rights issue and another GBP 7.5bn in an exchange offer: as part of the bailout in 2008, LBG was not allowed to pay coupons on certain hybrid securities or redeem them between January 31, 2010 and January 31, 2012 (Lloyds Banking Group, November 3, 2009a ${ }^{4}$ ). For this reason, in December 2009, LBG offered its claim holders to swap certain outstanding hybrid capital for CoCos, so called Enhanced Capital Notes (Lloyds Banking Group, November 3, 2009b . Coupons range between the 3-month Euribor plus 310bp for maturity in 2020 (ISIN: XS0459090931) and 16.126\% for CoCos maturing in 2024 (ISIN: XS0459093281).

In a nutshell, LBG pursued several goals by the CoCo issue. First, the bank wanted to withdraw from the GAPS which would have required high fees. Second, the bank wanted to continue its operations privately and without the involvement of the state. Third, issuing CoCos enabled LBG to make coupon payments to its bondholders again. And lastly, as stated in Section 0, banks have an incentive to issue CoCos in order to meet the Basel III requirements coming into effect gradually until 2019. In this case, the advantages of CoCos can be viewed as regulatory-driven rather than economically and financially motivated.

\subsection{Conversion Risk and Capital Structure}

A bank that has CoCos outstanding cannot go bankrupt because of these CoCos. Nevertheless, it can get into trouble when the amount of debt is too high relative to the core capital. Referring to LBG, this would be the case if the core tier 1 ratio (as defined as ${ }^{5} \mathrm{CT} 1$ ratio $=\mathrm{CT} 1$ capital/Risk-weighted assets) falls below $5 \%$. As capital structures are changing throughout the year, there is always a certain risk that the trigger is hit. It is therefore

\footnotetext{
${ }^{3}$ Highest tier 1 capital coupon in 2011 was 13\% (ISIN: XS0408620135, XS0408620721), highest CoCo coupon was 16.125\% (ISIN: XS0459093281).

${ }^{4} \mathrm{~A}$ list of the affected securities is enclosed in this document too.

${ }^{5}$ See letter from the Financial Services Authority to the British Bankers Association (Financial Services Authority, May 1, 2009) for the exact definition of this ratio.
} 
interesting to see the evolution of the conversion risk over different fiscal years. The aim of this subsection is to assess the risk that LBG's CoCos are converted to equity.

An easy way to decrease the CT1 capital ratio and trigger a conversion is via negative earnings. Highly volatile earnings increase the conversion risk, as profits and losses are directly booked into the equity account. That is, when high losses occur, it is possible that the CT1 capital becomes too low to yield a CT1 ratio of above 5\%.

Figure 1 shows that the risk-weighted assets have decreased considerably while the CT1 capital has remained relatively constant. The conversion risk has thus fallen constantly. At first glance the increasing CT1 ratio might suggest that the bank is resistant to economic shocks. However, it is insightful to look at the two sources that may change the ratio as the bank cannot control these components equally easily.

Figure 1. Core tier 1 ratio, core tier 1 capital and risk-weighted assets of LBG

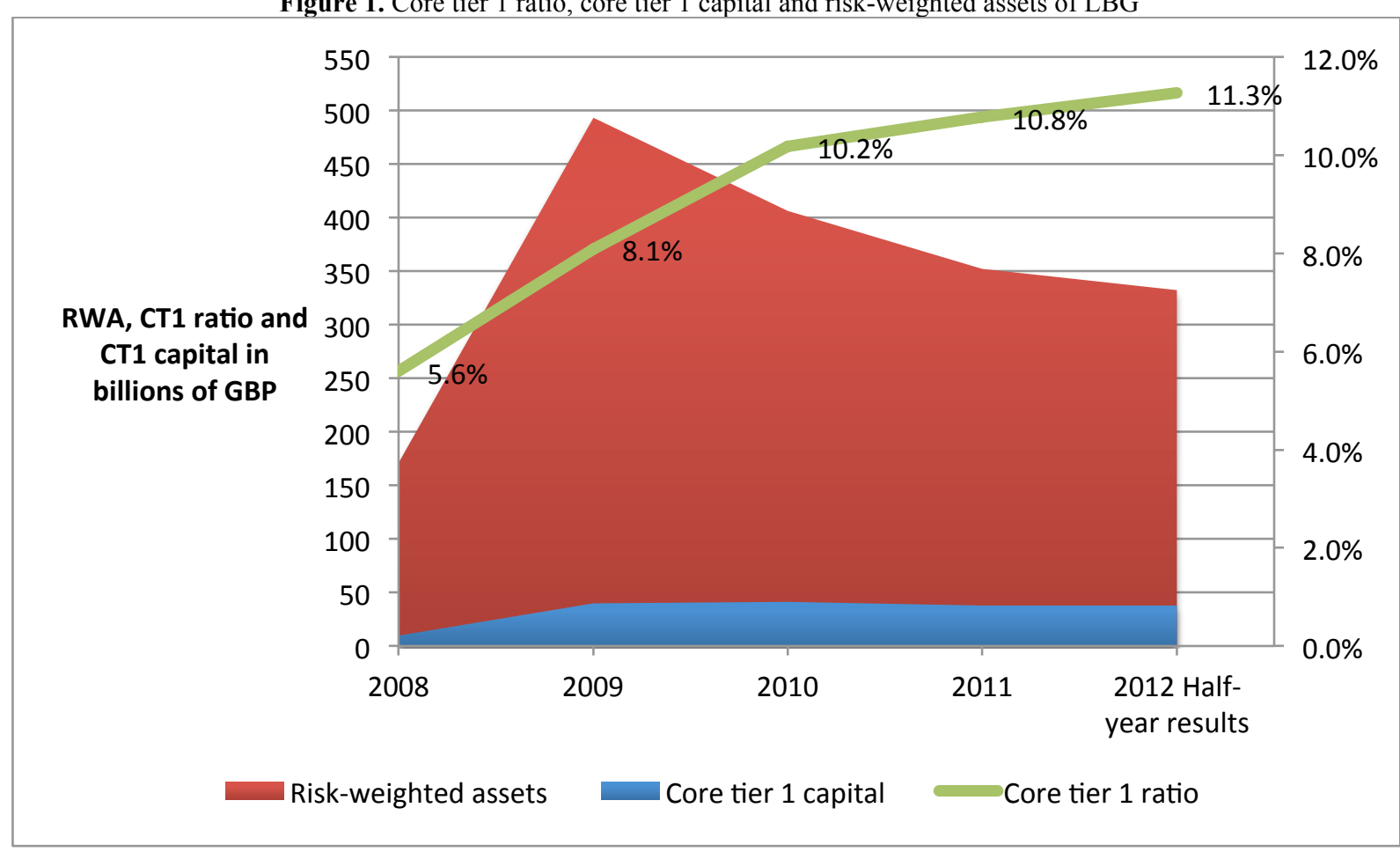

The CT1 capital consists of the common capital stock and retained earnings. The bank can only use these funds to compensate losses. Due to the fact that losses are more or less unpredictable and hard to control, the CT1 capital can change unexpectedly. According to Figure 2, past earnings have indeed been extremely volatile nevertheless, there was still enough CT1 capital to absorb those losses. In contrast, risk-weighted assets can be controlled when the bank manages its risk profile actively. An issue of unsecured loans raises the risk-weighted assets, whereas an issue of secured loans improves them. 
Figure 2. Profits and losses of LBG between 2008 and 2012

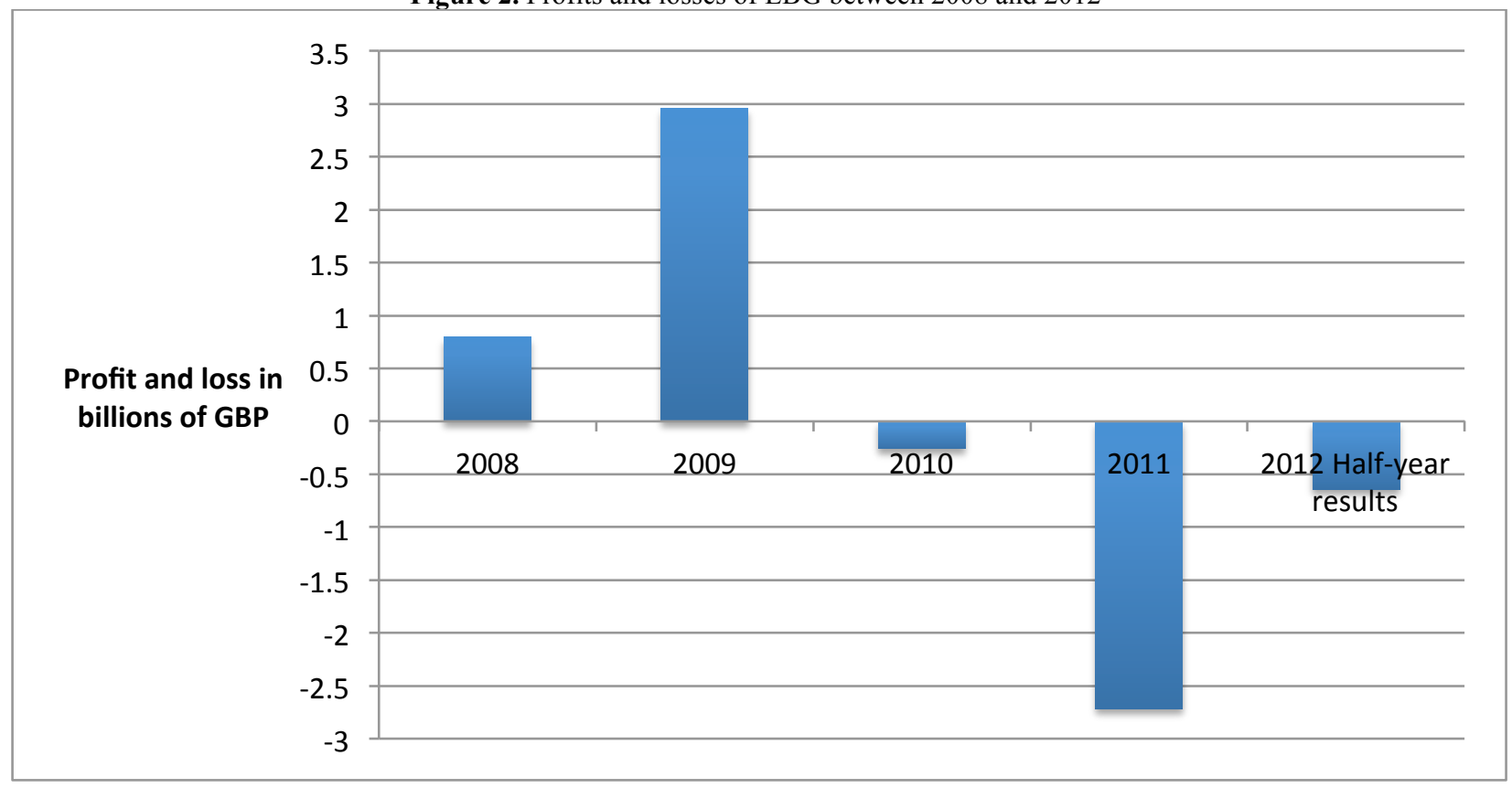

In a nutshell, the conversion risk has decreased over the past few years. However, given that LBG follows a high risk strategy, an approach that focuses on the enhancement of the CT1 capital instead of the pure reduction of risk-weighted assets would lead to an even lower conversion risk.

A second factor that strongly influences the conversion risk is the height of the conversion trigger. The CT1 ratios of lately above $10 \%$ are far away from the critical threshold of $5 \%$. I.e., a conversion into equity is very unlikely and only triggered when the capital ratio drops by more than 5 percentage points. This would only happen in very extreme situations and the CoCos would serve as 'catastrophe bonds' (Zaehres 2011, 6). The contribution of the trigger to the conversion risk is therefore rather small. At the moment of the issue, the bank's CT1 capital ratio amounted to roughly $8 \%$, so the investors knew that a conversion would be quite unlikely when they bought the bonds.

Third, the CT1 ratio can be affected when the equity value changes drastically. Economic shocks, low earnings announcements and other adverse effects can thus increase the conversion risk. This is particularly important when we think of stock price manipulation, which can cause a decline in stock prices such that LBG's CT1 capital ratio reaches the critical value of $5 \%$. Furthermore, when we assume that the conversion probability is already very high, the CoCo bondholders require a higher premium for the risk they bear. The bank has to pay higher premiums on the coupons, which leads to a downward spiral since the earnings fall and lower the CT1 capital in turn.

\subsection{Event Studies}

\subsubsection{Effect on Stock Prices}

In order to analyze the effects of the announcement of the issue of CoCos, we carry out an event study under the null hypothesis that the event under investigation has no significant effect on the value of the firm.

In the following analysis we examine if the event had an effect on the equity returns and, if so, in which direction. For this purpose two opposing effects can be considered. On the one hand, when CoCos are issued, they increase the amount of outstanding bonds on which the bank has to pay coupons. Consequently, additional CoCos increase the conversion probability. Once the debt is converted to equity the initial shareholders suffer a dilution of 
their shares. These two effects should force the stock prices down. On the other hand, a default becomes much more unlikely as new equity is created once the trigger is hit. Therefore the stock prices should go up.

It is difficult to define the actual event date due to public rumors and speculation in the media some days prior to LBG's announcement that it would withdraw from the GAPS. Moreover, LBG made public on October 29 (day -3) that it was considering withdrawing from the GAPS and finding a public sector solution. It would be possible to follow the suggestions of Ball \& Torous (1988) to use maximum likelihood estimation when the exact event day is uncertain. It is, however, common practice to include the 20 days prior to and the 20 business days after the event date. The event period thus runs from October 6 (day -20) to December $1($ day +20$)$ of the year 2009.

The estimation period is defined as follows. In order to create a benchmark for the expected returns of LBG's common equity, we cover an estimation window of 120 business days prior to the event window (day -140 to day -21), therefore running from late April to early October 2009. According to the method proposed by MacKinlay (1997) we set up a market model in order to define a reference point for the 'normal' stock returns, presuming the CoCo issue announcement had never happened. As we assume a linear relationship between the market portfolio returns and the single firm returns, the market model is a simple regression:

$$
R_{t}=\alpha+\beta R_{m t}+\varepsilon_{t}
$$

where $R_{t}$ and $R_{m t}$ denote the returns in period t for LBG and the FTSE All-Share Index, respectively. The resulting regression coefficients, $\hat{\alpha}$ and $\hat{\beta}$, are then used to estimate the expected returns for every point in time $\tau$ during the event period using the market return $\mathrm{R}_{\tau}$ :

$$
\hat{R}_{\tau}=\hat{\alpha}+\hat{\beta} R_{m \tau}
$$

Afterwards, abnormal returns for the event period are computed by subtracting the estimated from the actual returns in the event period:

$$
\begin{aligned}
A R_{\tau} & =R_{\tau}-\hat{R}_{\tau} \\
& =R_{\tau}-\hat{\alpha} \cdot-\hat{\beta} R_{m \tau}
\end{aligned}
$$

where $R_{m \tau}$ is the actual return in period $\tau$ of the event period. In this step we assume that there is a premium (an abnormal return) on the normal returns that is due only to the occurrence of the event.

Summing up the abnormal returns yields the cumulative abnormal returns (CARs) which are reported in Figure 3. They are used to compute the t-values in order to draw inferences. The null hypothesis is that the CARs are zero, i.e. that the event had no significant effect on the equity returns. The results are reported in Table 1. 
Figure 3. Cumulative abnormal returns around the announcement date



Table 1. ARs, CARs and t-values around the event on November 3, 2009

\begin{tabular}{llcccc}
\hline \multicolumn{1}{c}{ Date } & Day & ARs & CARs & t-value & (p-value) \\
\hline October 28 & -4 & $-4.20 \%$ & $-11.52 \%$ & -2.50 & $(0.01)^{*}$ \\
October 29 & -3 & $-7.30 \%$ & $-18.82 \%$ & -4.08 & $(0.00)^{* *}$ \\
October 30 & -2 & $14.50 \%$ & $-4.32 \%$ & -0.94 & $(0.35)$ \\
November 2 & -1 & $-7.65 \%$ & $-11.97 \%$ & -2.59 & $(0.01)^{* *}$ \\
November 3 & 0 & $0.09 \%$ & $-11.87 \%$ & -2.57 & $(0.01)^{* *}$ \\
November 4 & 1 & $6.34 \%$ & $-5.53 \%$ & -1.20 & $(0.23)$ \\
November 5 & 2 & $-6.26 \%$ & $-11.79 \%$ & -2.55 & $(0.01)^{* *}$ \\
November 6 & 3 & $-1.42 \%$ & $-13.20 \%$ & -2.86 & $(0.01)^{* *}$ \\
November 9 & 4 & $2.16 \%$ & $-11.05 \%$ & -2.39 & $(0.02)^{*}$ \\
November 10 & 5 & $-0.75 \%$ & $-11.80 \%$ & -2.56 & $(0.01)^{* *}$ \\
November 11 & 6 & $1.30 \%$ & $-10.50 \%$ & -2.27 & $(0.02)^{*}$ \\
\hline
\end{tabular}

$* \mathrm{p} \leq 0.05, * * \mathrm{p} \leq 0.01$

The t-statistic on day 0 turns out to be significant at the $1 \%$ level. We can witness CARs of $-11.87 \%$ until that day. This seems plausible when we consider that LBG's stockholders have already suffered huge losses because of the acquisition of HBOS and thus react negatively to actions that further decrease their wealth. It is evident that the market already reacted to the announcement made on October 29, and that this anticipation effect is remarkable. The CARs of $-18.82 \%$ on that day are significant at the $1 \%$ level. Also on the days before and after day 0 , the CARs are mostly significant at the 1 or $5 \%$ level $^{6}$. To conclude, one can say that the perception of the negative effects of the CoCo issue (namely diluted shares of the initial stockholders) is much stronger than that of the positive effects.

\footnotetext{
${ }^{6}$ The CARs on day 18 (November 27) are highly negative: on that date, the trade of the newly issued shares has started and the initial equity
} holders' shares diluted. 


\subsubsection{Effect on CDS spreads}

When it comes to new securities, a great challenge for credit rating agencies is the assessment of the creditworthiness of the bank and the risk that the claims cannot be entirely paid back. (Good) ratings are of great importance for the marketability of securities because European institutional investors are usually bound by contract to include only investment grade bonds in their portfolios (i.e. bonds that have a rating better than Ba1/BB+). Another restriction is that institutional investors are often not allowed to buy mandatory convertibles (DeSpiegeleer \& Schoutens 2012). This worsens the domino effect problem because it limits the potential investor target audience to banks. When only banks buy other banks' CoCos, the banking system destabilizes since a default of a single body would pull many other banks to the ground. Obviously, both the issuing bank and the whole financial system heavily depend on the securities' rating. The marketability of CoCos in Europe is currently questionable due to the fact that the major rating agencies currently abstain from rating CoCos.

Another way to capture the market's sentiments towards LBG's creditworthiness is through credit default swap (CDS) spreads. CDS spreads are prices for an insurance against the insolvency of a firm and a very good proxy for the default probability. They reflect the market sentiment on a daily basis, while credit rating updates are released much more infrequently. The market is modeled by the iTraxx Europe. The criteria for the identification of the estimation and event periods are the same as in the event study in Section 0, but due to different treatments of holidays the 120 pre-event days now run from April 21 (day -140) to October 5 (day -21). The event period covers the days from October 6 (day -20) to December $1($ day +20$)$. The event day itself remains unchanged. The methodology is the same as in Section 0.

An educated guess concerning the direction of the CDS spread evolution after LBG's announced its intention to issue CoCos could be the following. On the one hand, CoCos are in principle a good solution for banks, as they make them more resistant to economic shocks and decrease the probability of a default. This should lower the price for an insurance against LBG's default, since a default becomes more unlikely. On the other hand, knowing the results from the first event study and bearing in mind that CDS spreads should be negatively correlated with the firm value (since a lower firm value implies a higher default probability), it is possible that the cumulative abnormal CDS spread changes from the following event study are positive. Figure 4 shows the cumulative abnormal CDS spread changes (CASCs), whereas the results of the test carried out on the CASCs are presented in Table 2. 
Figure 4. Cumulative abnormal CDS spread changes around the announcement date



The CASCs rise significantly after the announcement made on November 3 . On the day of the announcement, a cumulative change in the premium for a CDS on LBG of $4.77 \%$ can be observed. As can be seen in Figure 4, this value rises even further when we extend the period of interest beyond this day. The reduction in creditworthiness may also be attributed indirectly to the issue of CoCos, i.e., these bonds enabled the bank to withdraw from the state insurance and thereby increased their default probability.

Table 2. Abnormal CDS spread changes, cumulative abnormal CDS spread changes and t-values around the event on November 3, 2009

\begin{tabular}{lccccc}
\hline \multicolumn{1}{c}{ Date } & Day & ASCs & CASCs & t-value & (p-value) \\
\hline October 27 & -5 & $-1.33 \%$ & $0.84 \%$ & 0.36 & $(0.72)$ \\
October 28 & -4 & $2.93 \%$ & $3.77 \%$ & 1.61 & $(0.11)$ \\
October 29 & -3 & $-0.33 \%$ & $3.44 \%$ & 1.47 & $(0.14)$ \\
October 30 & -2 & $1.49 \%$ & $4.93 \%$ & 2.11 & $(0.04)^{*}$ \\
November 2 & -1 & $-0.22 \%$ & $4.72 \%$ & 2.02 & $(0.05)^{*}$ \\
November 3 & 0 & $0.05 \%$ & $4.77 \%$ & 2.04 & $(0.04)^{*}$ \\
November 4 & 1 & $2.88 \%$ & $7.65 \%$ & 3.27 & $(0.00)^{* *}$ \\
November 5 & 2 & $1.79 \%$ & $9.44 \%$ & 4.04 & $(0.00)^{* *}$ \\
November 6 & 3 & $2.61 \%$ & $12.05 \%$ & 5.15 & $(0.00)^{* *}$ \\
\hline
\end{tabular}

$* \mathrm{p} \leq 0.05, * * \mathrm{p} \leq 0.01$

\section{CONCLUSION}

In this case study the main reasons for LBG's CoCo issue in 2009/2010 as well as the consequences of a CoCo placement for banks were outlined. Make banks more resistant to economic shocks, they are in line with the European Basel III regulations and can be counted towards the tier 1 capital once converted. Furthermore, CoCos transfer the responsibility for bearing the costs for a bad bank performance from the taxpayer to the owners of the bank, diminishing the 'too big to fail' problem. This is a good fundament to restore trust in the banking system. It is logical that, due to the risks that potential CoCo bondholders will bear, there have to be high premiums compared to straight bonds, which can make up several percentage points. Hence, CoCos are a good investment for people who are not very risk averse towards conversion and seeking high coupons. 
The first event study analyzed the stock market's reaction to LBG's CoCo issue announcement. The results are consistent with the hypothesis that the stockholders do not appreciate the issue because they may fear the dilution of their shares when the bonds are converted into new common stock. Moreover, the issue proves to make the insurance against a default more expensive. This can be attributed to the fact that LBG preferred the CoCo issue to the government rescue plan. It is evident that LBG's CoCos were not in the position to convey positive information to the CDS or the stock market.

\section{REFERENCES}

Albul, B., Jaffee, D. M. \& Tchistyi, A. (2010), Contingent Convertible Bonds and Capital Structure Decisions, 2013 Meeting Papers 682, Society for Economic Dynamics.

Ball, C. A. \& Torous, W. N. (1988), Investigating Security-Price Performance in the Presence of Event-Date Uncertainty, Journal of Financial Economics 22(1), 123-153.

BBC News (2009), Taxpayer 'set to control Lloyds'. Retrieved from http://news.bbc.co.uk/2/hi/business/7927415.stm

De Spiegeleer, J. \& Schoutens, W. (2012), Pricing Contingent Convertibles: A Derivatives Approach, Journal of Derivatives 20(0), 27-36.

Financial Services Authority (2009), Definition of Core Tier 1 Capital. Retrieved from http://www.fsa.gov.uk/pubs/other/bba_letter.pdf

Financial Times (2011), Rabobank sells \$2bn in contingent capital. Retrieved from http://www.ft.com/intl/cms/s/0/5dd702ba-23d6-11e0-8bb1-00144feab49a.html

Flannery, M. J. (2009), Stabilizing Large Financial Institutions with Contingent Capital Certificates, Working Paper, University of Florida.

Lloyds Banking Group (2009a), Lloyds Banking Group - Hybrid Capital Securities. Retrieved from http://hsprod.investis.com/ir/lloy/pdf/hybrid_capital_securities16_03_10.pdf

Lloyds Banking Group (2009b), Proposed Alternative to the Government Asset Protection Scheme comprising a rights issue and liability management exercise by way of exchange offers. Retrieved from http://www.lloydsbankinggroup.com/globalassets/documents/investors/2009/2009nov3_lbg_gaps_alternati ve_rights_issue.pdf

MacKinlay, A. C. (1997), Event Studies in Economics and Finance, Journal of Economic Literature, 35(1), 13-39.

Marquardt, C. A. \& Wiedman, C. I. (2007), Economic Consequences of Financial Reporting Changes: Diluted EPS and Contingent Convertible Securities, Review of Accounting Studies, 12(4), 487-523.

O'Brien, P. C. (2005), Discussion of Earnings Management through Transaction Structuring: Contingent Convertible Debt and Diluted Earnings per Share, Journal of Accounting Research, 43(2), 245-25.

Pelger, M. (2012), Contingent Convertible Bonds: Pricing, Dilution Costs and Efficient Regulation, Working Paper \#2012-02, University of California Berkeley.

Reuters (2011), Allianz kick-starts insurance CoCo bond market. Retrieved from http://uk.reuters.com/article/2011/07/05/businesspro-us-allianz-nipponlifeidUKTRE7643NF20110705

The Guardian (2009), Government takes over Lloyds. Retrieved from http://www.theguardian.com/business/2009/mar/07/government-takes-over-lloyds

The Telegraph (2011), Bank CoCo bond market could be worth $£ 590 \mathrm{bn}$. Retrieved from http://www.telegraph.co.uk/finance/newsbysector/banksandfinance/8309391/Bank-CoCo-bond-marketcould-be-worth-590bn.html

Wilkens, S. \& Bethke, N. (2014), Contingent Convertible (CoCo) Bonds: A First Empirical Assessment of Selected Pricing Models, Financial Analysts Journal, 70(2), 59-77.

Zaehres, M. (2011), Contingent Convertibles: Bonds take on a new look, EU Monitor 79, Deutsche Bank Research, $1-19$. 